\title{
Axial compression capacity of concrete columns reinforced with corrosion-resistant metallic reinforcement
}

\author{
John W. Wright ${ }^{1}$ and Chris P. Pantelides ${ }^{2^{*}}$ (D)
}

\begin{abstract}
Axial compression performance of concrete columns reinforced with 2304 solid stainless bars and spirals, carbon steel bars and spirals, and $316 \mathrm{~L}$ stainless steel clad bars is examined after the columns are exposed to severe corrosion. Two groups of columns were investigated: a control group, and a group submerged in a $5.0 \%$ by weight chloride solution subjected to accelerated corrosion. A relatively high impressed current density of $8.5 \mu \mathrm{A} / \mathrm{mm}^{2}$ was used and after 60 days of accelerated corrosion the columns were tested to failure under axial compression. In terms of mass loss per unit of corrosion energy, columns reinforced with stainless steel spirals and either solid stainless or stainless clad vertical bars were 197\% more corrosion resistant than carbon steel. Bars made with 2304 solid stainless steel and $316 \mathrm{~L}$ stainless clad materials developed localized pitting corrosion that led to degradation of the concrete cover and a larger drop in axial compression than carbon steel reinforced columns. However, the carbon steel reinforced columns reached lower failure displacements and a corroded carbon steel reinforced column was the only column to experience sudden failure prior to reaching its theoretical maximum axial compression capacity. Axial compression capacity of the columns in both the control and corroded conditions was modeled using concrete confinement models that produced good agreement with the experimental results.
\end{abstract}

Keywords: Carbon steel, Column, Compression test, Concrete, Confinement, Corrosion test, Stainless clad, Stainless steel

\section{Introduction}

Concrete structures reinforced with conventional carbon steel are susceptible to corrosion. This research applies to areas where concrete structures face severe deterioration due to corrosion of reinforcement, such as: (1) areas where the service-environment for concrete structures near seawater is characterized by adverse climatic conditions, namely severe salinity and high temperaturehumidity; and (2) areas where anti-icing and de-icing brines used during harsh winter seasons cause premature degradation of the highway infrastructure. To mitigate or control corrosion, stainless steel bars, stainless

\footnotetext{
* Correspondence: c.pantelides@utah.edu

${ }^{2}$ Department of Civil and Environmental Engineering, University of Utah, 110

Central Campus Drive, Room 2115, Salt Lake City, UT 84112, USA

Full list of author information is available at the end of the article
}

clad bars that have a carbon steel core with stainless cladding, and glass fiber reinforced polymer (GFRP) composite bars are currently being considered as alternative reinforcing materials. The initial cost of such corrosion-resistant bars is greater than carbon steel; however, the life-cycle cost including maintenance and repair might eventually be less.

Reinforcement with a carbon steel core and outer austenitic stainless steel cladding and stainless steel with a dual-phase austenitic and ferritic microstructure, is reported to resist corrosion better than carbon steel or epoxy coated carbon steel bars [1]. Another option for corrosion-resistant reinforcement is 2304 solid stainless steel (alloy including 23\% chromium and 4\% nickel); this material is reported to have higher corrosion resistance than carbon steel and lower cost than stainless steel bars 
and stainless clad bars [2]. Similar performance has been reported regarding stainless clad bars and solid stainless bars; stainless clad bars with $0.25 \mathrm{~mm}$ to $0.8 \mathrm{~mm}$ thick $316 \mathrm{~L}$ austenitic stainless steel cladding have been reported as providing the best performance [3].

Results of an experimental study on the corrosion of S11203 stainless steel bar under different strain levels have been presented [4]; the strain level affected the degree of corrosion of stainless steel bar in that the higher the strain, the higher the degree of corrosion. The degree of corrosion of the specimen under a strain of $1.0 \times$ $10^{-3}$ was $9 \%$ higher than that of under zero strain. The degradation rate of nominal strength and elongation of stainless steel bars were higher than those of ordinary steel bars. However, even when the degree of corrosion reached 25\%, the nominal strength of stainless steel bars was generally higher than most ordinary steel bars.

Accelerated corrosion tests of S23043 in a chloride environment and tensile tests of the corroded steel bars were carried out to investigate the effect of strain level on the corrosion degree and mechanical properties [5]. The corrosion of S23043 was non-uniform, mainly pit corrosion; with increasing time, corrosion pits showed a tendency to form mutual connections but strain levels had no effect on the corrosion morphology. Compared with the mechanical properties of ordinary steel bars after corrosion, as the corrosion degree increased, the yield strength and ultimate strength of S23043 degraded more quickly than that of ordinary steel bars, and the elongation of S23043 degraded more quickly than that of ordinary steel bars.

The corrosion behavior of $304 \mathrm{~L}$ and $316 \mathrm{LN}$ stainless steel clad reinforcing bars has been studied [6]. Bars tested in cracked concrete showed active corrosion at the base of the crack, which extended along the rebar length. There was no significant difference in the active and passive corrosion rates between the clad and the solid stainless steel bars in cracked concrete after exposure to $21 \%$ chloride brine.

It has been projected that GFRP bars encased in concrete could retain over $70 \%$ of their tensile capacity, after continued submersion in tap and salt water for a 100year service life [7]. Degradation of GFRP bars from exposure to chlorides has been reported to be insignificant [8]; moreover, immersion of GFRP reinforced columns in distilled water and chloride saturated water showed superior retention of long term capacity compared to carbon steel reinforced columns [9]. Concrete columns reinforced with carbon steel longitudinal bars and GFRP spiral had very little corrosion compared to carbon steel columns [10]. Confinement using GFRP spiral differs from confinement using a carbon steel spiral because the modulus of elasticity of GFRP is low; however, this is a promising reinforcing option and analytical models have been proposed to predict the efficiency of GFRP spiral for concrete confinement [11].

This research aims to show whether $316 \mathrm{~L}$ stainless clad reinforcing bars could provide similar corrosion resistance as 2304 solid stainless bars in concrete columns exposed to aggressive environments. Specifically, the loss in axial load capacity of corroded concrete columns reinforced with $316 \mathrm{~L}$ stainless clad or 2304 solid stainless bars is investigated. Moreover, the axial load performance of columns reinforced with $316 \mathrm{~L}$ stainless clad or 2304 solid stainless bars is compared to that of columns reinforced with carbon steel under both uncorroded and corroded conditions. The study examines the axial capacity of corroded concrete columns rather than the deterioration of individual bars. Greater use of corrosion resistant reinforcement is anticipated and this research highlights the performance of two economical reinforcement options under aggressive environments. The potential for delamination of the cladding from the core of stainless clad bars under axial compression for corroded concrete columns has not been studied widely.

The performance of corrosion-resistant metallic reinforcement is investigated using accelerated corrosion tests followed by concentric axial compression tests to failure. Three categories of medium-scale concrete column specimens were tested: (a) columns reinforced with 2304 solid stainless steel vertical bars and spirals; (b) columns reinforced with $316 \mathrm{~L}$ stainless steel clad vertical bars and 2304 solid stainless steel spirals; and (c) columns reinforced with carbon steel vertical bars and spirals; the latter series was tested for comparison to the corrosion-resistant reinforced columns. Accelerated corrosion was achieved by subjecting the concrete column specimens to 60 days of corrosion with impressed direct current potential. Concrete cracking and spalling were recorded and compared during the accelerated corrosion experiments. The amount of theoretical mass loss based on recorded current was obtained from Faraday's law. After the 60-day accelerated corrosion process, the specimens from the three column series were tested under concentric axial compression; this also enabled close examination of the degree of corrosion of the reinforcement. Corroded as well as control columns were tested for the three series; the theoretical capacity of control and corroded concrete columns was determined using the model proposed by Mander et al. [12]. The overall performance of corroded columns was compared as a function of the total corrosion energy experienced by the reinforcement.

The main objective of this study was to investigate the serviceability and performance of concrete columns reinforced with carbon steel, 2304 solid stainless steel, and $316 \mathrm{~L}$ stainless steel clad bars and spirals under corrosive conditions. A second objective was to investigate the axial compressive strength of corroded and control medium-scale columns reinforced with 2304 solid 
stainless steel bars and spirals, columns reinforced with $316 \mathrm{~L}$ stainless clad vertical bars and 2304 solid stainless steel spirals, and columns reinforced with carbon steel vertical bars and spirals. A third objective was to predict the axial compressive strength of corroded and control columns using concrete confinement models.

\section{Material selection and specimen design}

The medium-scale columns were $810 \mathrm{~mm}$ tall with a $305 \mathrm{~mm}$ diameter. The columns were cast with peagravel concrete and cured for 28 days. The concrete mix design is given in Table 1. Concrete cylinders $203 \mathrm{~mm}$ tall with a $102 \mathrm{~mm}$ diameter were cast; the 28-day concrete compressive strength was found as $29 \mathrm{MPa}$. The column axial compression tests were carried 300 days after casting the concrete; the compressive strength of the concrete cylinders at 300 days was $45 \mathrm{MPa}$.

Carbon steel bars and spirals were Grade 60 reinforcement. The carbon steel bars and spirals were the first series of columns (BB series); 2304 solid stainless steel bars and spirals comprised the second series (NN series), whereas $316 \mathrm{~L}$ stainless steel clad bars and 2304 solid stainless steel spirals was the third series $(\mathrm{CN}$ series). A total of 11 columns were cast, six of which were subjected to current-accelerated corrosion (referred to as corrosion or " $\mathrm{R}$ " specimens); the remaining five columns were subjected to room temperature conditions (referred to as control or "C" specimens). Figure 1 shows the dimensions of a typical concrete column and reinforcement details. All vertical bars were $16 \mathrm{~mm}$ in diameter; both carbon steel and 2304 solid stainless steel spiral reinforcement had a $13 \mathrm{~mm}$ diameter. The spirals had an external diameter of $211 \mathrm{~mm}$ and a pitch equal to $57 \mathrm{~mm}$. The reinforcement combinations are given in Table 2. Each corroded specimen had copper wires attached to the reinforcement connected to a power supply during the corrosion period, as shown in Fig. 2.

\section{Current-accelerated corrosion experiments}

A method similar to the Florida Department of Transportation procedure was used to accelerate corrosion of the reinforcement of the concrete column specimens $[13,14]$; in this method, the specimens were submerged up to half their height in a $5.0 \%$ by weight $\mathrm{NaCl}$ saltwater solution and an electrical potential was applied to

Table 1 Mix design of concrete per $1 \mathrm{~m}^{3}$

\begin{tabular}{lll}
\hline Components & Weight, $\mathbf{k g}$ \\
\hline Cement & Type II & 328.7 \\
Water & & 119.7 \\
Coarse aggregate & Pea gravel mix & 658.9 \\
Sand & & 1047.0 \\
Fly ash & 72.93 \\
\hline
\end{tabular}

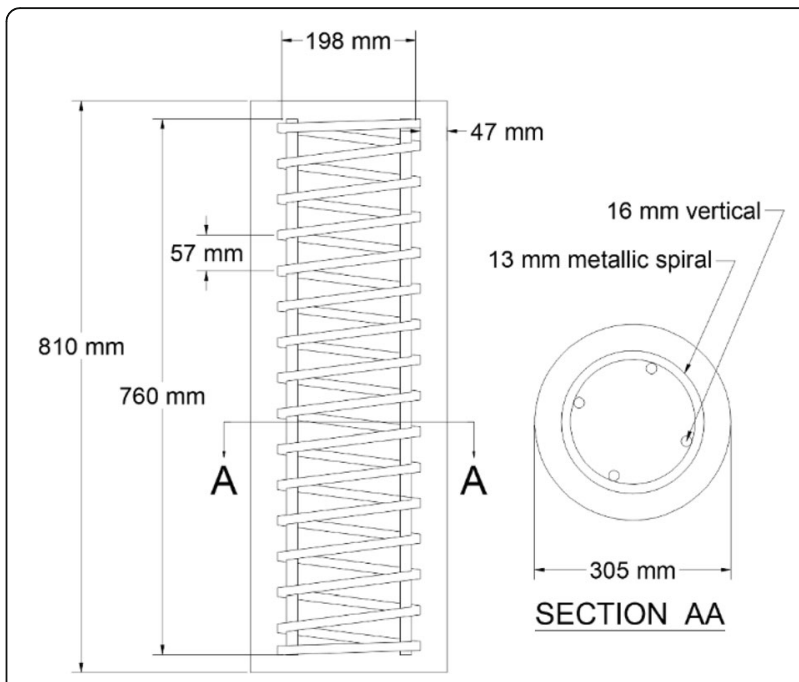

Fig. 1 Concrete column specimen dimensions and reinforcement

the metallic reinforcement. The rate of corrosion was regulated using current density; this is defined as the amount of induced current divided by the surface area of steel exposed to the chloride solution. It is well known that a $2.0 \mu \mathrm{A} / \mathrm{mm}^{2}$ current density induces significant acceleration in the rate of strain-crack formation in concrete [14]. High levels of impressed current density have been used in accelerated corrosion tests by several researchers for the following reasons: (1) on the basis of pilot tests to provide desired levels of corrosion in a reasonable time; and (2) for corrosion tests of specimens constructed with steel fiber-reinforced concrete, where the current density can reach up to many times higher than the current density for conventional concrete specimens.

The effect of varying the impressed current density level on concrete strain, crack width, and mass loss of reinforcing bars due to expansive stresses caused by corrosion products in concrete prisms has been studied [14]; it was concluded that: (1) current density levels between 1.0 and $5.0 \mu \mathrm{A} / \mathrm{mm}^{2}$ had no effect on the concrete side strain response up to $0.8 \%$ mass loss but at higher degrees of corrosion, increasing the current density level above $2.0 \mu \mathrm{A} / \mathrm{mm}^{2}$ resulted in a significant increase in the concrete side strain; and (2) inducing corrosion using low current density levels requires a longer corrosion period than that required to reach the same percentage of mass loss at higher current density levels. A current density of $20.0 \mu \mathrm{A} / \mathrm{mm}^{2}$ has been used on the basis of pilot tests to provide desired levels of corrosion in a reasonable time [15]; pullout and beam tests were carried out to study the influence of reinforcing bar corrosion and cracking on bond behavior and bond strength of reinforced concrete members. The critical slip in the post-cracking corrosion stage for the 
Table 2 Summary of specimen materials and dimensions

\begin{tabular}{llll}
\hline Specimen Type & Number of Specimens & Vertical Bar & Spiral Material \\
\hline BB-R & 2 & Carbon Steel & Carbon Steel \\
BB-C & 2 & Carbon Steel & Carbon Steel \\
NN-R & 2 & 2304 Stainless & 2304 Stainless \\
NN-C & 2 & 2304 Stainless & 2304 Stainless \\
CN-R & 2 & 316 L Stainless Clad & 2304 Stainless \\
CN-C & 1 & 316 L Stainless Clad & 2304 Stainless \\
\hline
\end{tabular}

$R$ Corroded, C Control

maximum corrosion level studied was found to be about 10 times the value at the normal zero corrosion situation.

A current density of $30.0 \mu \mathrm{A} / \mathrm{mm}^{2}$ was used to study the effect of corrosion on flexural behavior of slabs [16]; in slabs with corroded bars, in the post-cracking stage, a bond-shear type of failure was indicated. Spalling of the concrete cover was basically due to the conjoint effect of shear cracks and transverse cracks caused by reinforcement corrosion. The ultimate flexural strength of slabs decreased progressively with the degree of corrosion of the embedded steel; reduction in the ultimate flexural strength of slabs with $5 \%$ reinforcement corrosion was $25 \%$, while it was $60 \%$ in slabs with $25 \%$ reinforcement corrosion. A current density of $104.0 \mu \mathrm{A} / \mathrm{mm}^{2}$ was used to study the effect of corrosion on bond strength [17]; at 7\% rebar corrosion, the rib profile loss was about $45 \%$, whereas at $12 \%$ rebar corrosion, the loss in rib profile was around 70\%; this explains the bar slippage mode of failure at about $12 \%$ corrosion level. Corrosion levels between 5 and $7 \%$ were observed to cause significant increase in crack width as well as loss of rib profile; this explains the sharp reduction in the bond strength from 30 to $70 \%$ in this range of corrosion.

In accelerated corrosion tests of cylindrical concrete specimens with a reinforcement diameter of $16 \mathrm{~mm}$, the corrosion current density of the steel fiber-reinforced concrete was up to 3.3 times higher than that of conventional concrete; this was because the connectivity of the reinforcement was extended to the steel fibers on the surface of the specimen, which affected the corrosion current density of the reinforcement [18].

Since the present study is targeting applications where concrete or fiber reinforced concrete structures are under severe deterioration due to corrosion under a longer time span within an accelerated time frame, a relatively high impressed current density of $8.5 \mu \mathrm{A} / \mathrm{mm}^{2}$ was used. By driving the corrosion in this manner and at this rate, the case where the protective chromium oxide patina could not be maintained on the stainless steel and stainless clad reinforcement could be examined; this simulates a worst-case scenario of aggressive environmental conditions and allows stainless steel and stainless

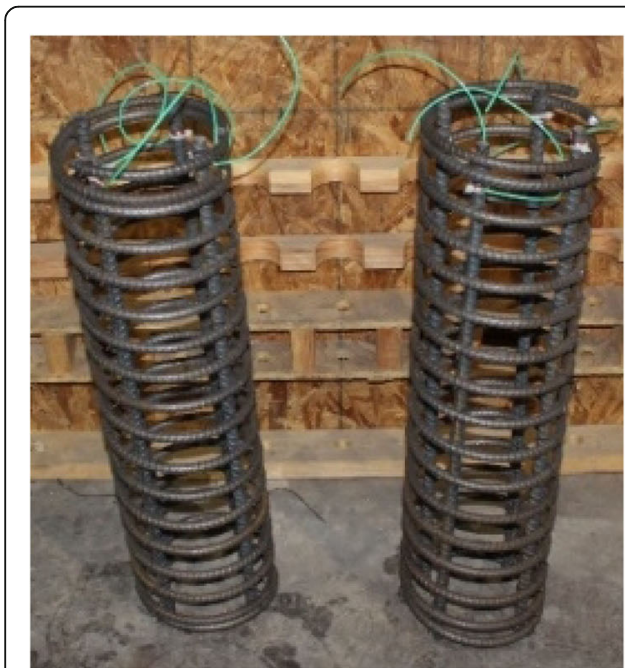

(a)

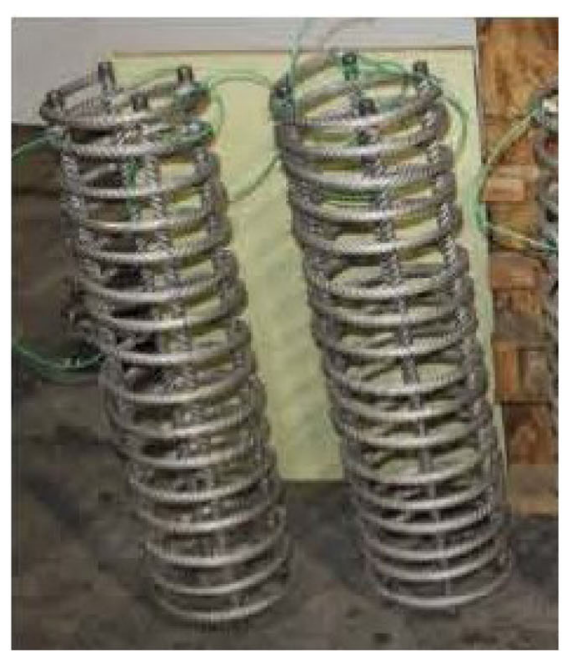

(b)

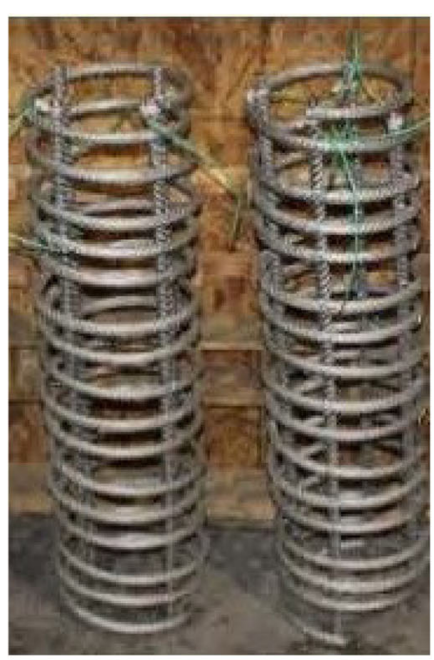

(c)

Fig. 2 Reinforcement of corroded specimens: a BB series; b CN series; c NN series 
clad bars to be tested in conditions where corrosion is guaranteed.

To allow infiltration of the electrolyte in the reinforcement before electrical potential was applied, the columns were submerged in saltwater (5\% by weight chloride solution) for a period of 2 weeks. Moreover, to complete the circuit through the electrolyte, a galvanized steel grate was placed at the bottom of the tank. Throughout the actual 60-day corrosion period, the target current density was maintained by measuring the current several times a week and adjusting the power. The average applied current was maintained to be within $15.0 \%$ of the target current. Voltage was read from the power supply and a constant rate of corrosion was maintained, with the measured current accounting for the potential applied by the power supply and the potential created by the internal corrosion cell of the corroding reinforcement.

The theoretical mass loss was calculated using Faraday's law from the average measured current as:

$$
M_{t h}=\frac{M_{A} I_{a p p} T}{\nu F}
$$

where $M_{t h}=$ theoretical mass loss in grams; atomic mass of the alloy $M_{A}$, was taken for carbon steel as 55.845 , the atomic mass of iron; for alloyed steel the weighted average atomic weight of individual components was used [19]; $M_{A}=56.352$ for 2304 solid stainless steel, and $M_{A}=$ 57.936 for $316 \mathrm{~L}$ stainless steel clad bars; $I_{a p p}$ is the average applied current in amps; $T$ is the total time of current application in seconds; $v$ is the valency of the corrosion product equal to 2.0; and $F=96487 \mathrm{amp}$-sec or Faraday's constant. It is well known that this method overestimates actual mass loss by a factor of 1.2; this was considered when finding the mass loss in Table 3 designated as the adjusted theoretical mass loss [20].

The measured voltage and current were used to calculate the total applied corrosion energy for each specimen, in terms of kilowatt hours using the following equation:

$$
E_{\text {total }}=V_{\text {avg }} I_{\text {avg }} T
$$

where $V_{\text {avg }}$ is the average applied voltage for the series during the testing period in kilovolts, $I_{\text {avg }}$ is the average measured current, and $\mathrm{T}$ is the duration of testing period in hours. The corrosion resistance of each specimen in terms of mass loss per unit of applied energy is expressed as:

$$
C R_{\text {mass }}=\frac{\% \text { mass loss }}{E_{\text {total }}}
$$

This value is calculated and shown in Table 3. Materials that exhibit a higher degree of mass loss per unit corrosion energy are less corrosion resistant for cases where other factors that contribute to total resistance in the system, such as depth of concrete cover, are similar. It is clear from Table 3 that columns reinforced with carbon steel have a higher degree of mass loss per unit corrosion energy by a factor of 1.9 compared to columns reinforced with stainless bars and spirals and columns reinforced with stainless clad vertical bars and stainless steel spirals.

The voltage fluctuated throughout the corrosion period, as conditions changed, and Fig. 3 illustrates the change in voltage over time. A drop in voltage occurred between day 5 and day 9 , with the voltage for the cladstainless $(\mathrm{CN})$ series and stainless-stainless $(\mathrm{NN})$ series dropping from 14.0 to $10.0 \mathrm{~V}$ and the carbon steelcarbon steel (BB) series dropping from 13.6 to $9.2 \mathrm{~V}$. This occurred as the concrete cover experienced splitting cracks due to radial stress, thus lowering the resistance required to maintain constant current density.

Cracking of the columns was observed on day 7 , when specimens began to show outward signs of corrosion, most notably NN-R-2 and BB-R-1, as shown in Fig. 4, where iron oxide effluent is deposited around the cracked concrete. Initial splitting cracks drive corrosion throughout the remainder of the test; this is true for stainless clad and stainless steel reinforcement where localized corrosion developed in regions where splitting cracks penetrated the concrete cover to the reinforcement. After the initial drop, between day 11 and 16 , the amount of voltage required to sustain the same rate of current-accelerated corrosion was much

Table 3 Summary of corrosion analysis

\begin{tabular}{llllll}
\hline Specimen & $\begin{array}{l}\text { Target Current } \\
\text { Density }\left(\boldsymbol{\mu} \mathbf{A} / \mathbf{m m}^{2}\right)\end{array}$ & $\begin{array}{l}\text { Measured Average Current } \\
\text { Density }\left(\boldsymbol{\mu} \mathbf{A} / \mathbf{m m}^{2}\right)\end{array}$ & $\begin{array}{l}\text { Adj. Theoretical } \\
\text { Mass Loss }(\mathbf{k g})\end{array}$ & $\begin{array}{l}\text { Adj. Theoretical \% } \\
\text { Mass Loss (\%) }\end{array}$ & $\begin{array}{l}\text { Mass Loss /Corrosion } \\
\text { Energy }(\% / K w h)\end{array}$ \\
\hline CN-R-1 & 8.50 & 8.89 & 1.53 & 21.0 & 1.5 \\
CN-R-2 & 8.50 & 6.82 & 1.18 & 16.1 & 1.5 \\
NN-R-1 & 8.50 & 7.75 & 1.34 & 18.4 & 1.5 \\
NN-R-2 & 8.50 & 9.53 & 1.64 & 22.6 & 1.5 \\
BB-R-1 & 8.50 & 11.52 & 1.99 & 27.2 & 2.9 \\
BB-R-2 & 8.50 & 7.80 & 1.38 & 18.9 & 2.9 \\
\hline
\end{tabular}




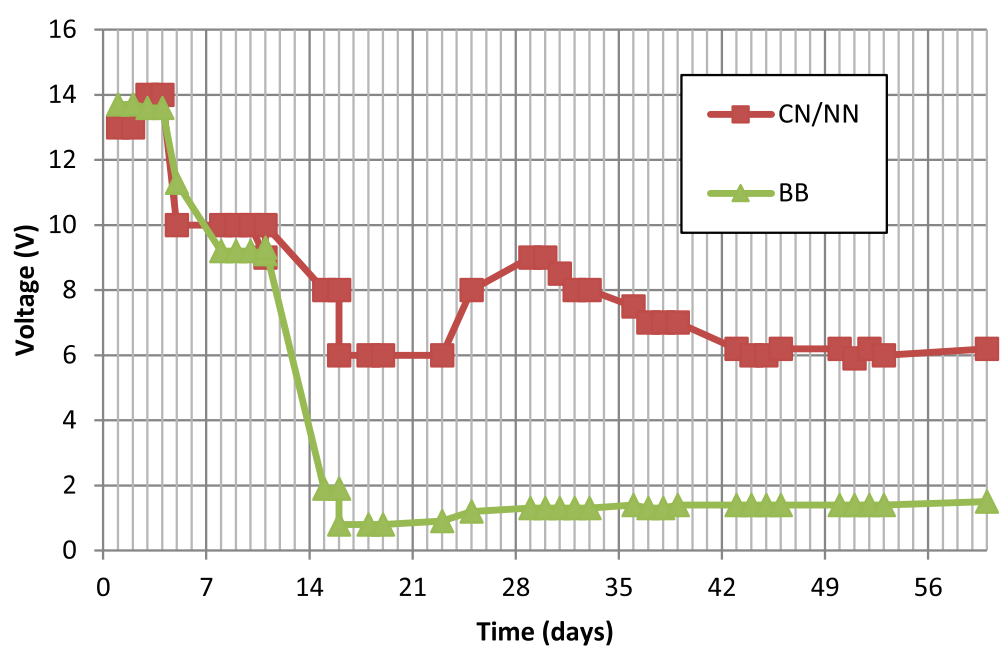

Fig. 3 Change in voltage over time

higher for the $\mathrm{CN}$ and $\mathrm{NN}$ series specimens at approximately 12 times the amount required for the BB series, even after similar amounts of cracking had occurred. The $\mathrm{CN}$ and $\mathrm{NN}$ series manifested another voltage drop between day 29 and 43, as shown in Fig. 3. Coloration observed from day 30 suggests that dissolved chromium or nickel was ejected as effluent. The development of more severe exterior cracking tended to precede large voltage drops, and in addition to the silver-colored effluent observed in the $\mathrm{CN}$ and $\mathrm{NN}$ series specimens, iron oxide effluent began forming between days 7 and 11, as noted in detail in Fig. 5.

After the 60-day corrosion period a wide extent of cracking was observed at the base of the $\mathrm{NN}$ and $\mathrm{CN}$ columns. Reconstitution of the cracked column bases involved reattachment of the cracked concrete pieces with grout and Carbon FRP wraps applied at the top and bottom $200 \mathrm{~mm}$ of the columns to ensure that failure would occur at the middle of the column height in the axial compression tests.
Examination of the specimens after testing confirmed that corrosion of stainless steel and stainless clad reinforcement was concentrated in smaller regions, whereas carbon steel experienced corrosion evenly over its surface. Much of the surface of stainless steel was unaffected, but there were regions in each of the stainless steel spirals where over $50 \%$ of the cross-sectional area had corroded. Figure 6 shows the distribution of these local pitting patterns on the spiral from column specimen NN-R-2, and a single corrosion pit in detail.

Prior to carrying out the axial compression tests, described in Section 4, it was observed that corroded specimens had external cracks extending at least into the middle third of the column height. After destructive testing, it was revealed that the degree of corrosion was greater along these cracks, especially in the spiral, as shown for specimen CN-R-1 in Fig. 7a. The affected points on the spiral were weak in resisting concrete dilation, as spirals with this corrosion pattern experienced sudden failure due to stress concentration at the thinner

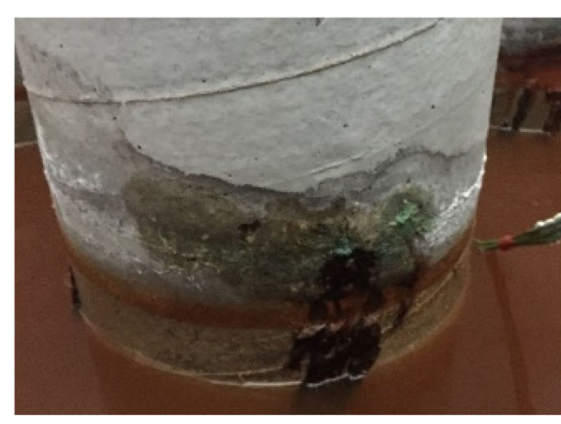

(a)

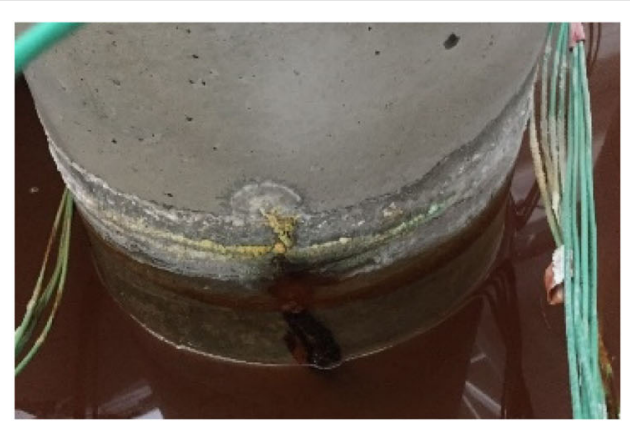

(b)

Fig. 4 External signs of corrosion on day 7: a specimen NN-R-2; b specimen BB-R-1 


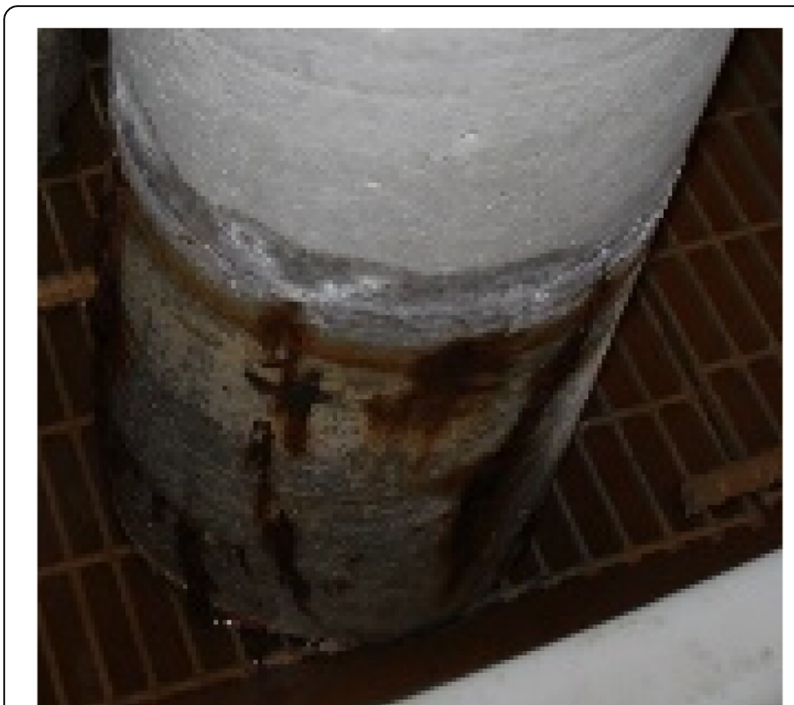

Fig. 5 External signs of corrosion on day 11 for specimen NN-R-1

areas where necking had occurred as shown in Fig. 7b. The degree of corrosion was not as severe in vertical stainless steel and stainless clad bars when compared to stainless steel spirals within the same column. Localized corrosion in the stainless steel spirals accounted for most of the mass loss, especially at the bottom portion of the columns.

The stainless steel end caps used to protect the core of the stainless clad bars corroded heavily. Figure $7 \mathrm{c}$ shows the leftover epoxy, the remaining portion of the stainless steel cap, and the core of the stainless clad bar, which had no sign of severe corrosion. The end caps acted as sacrificial anodes, which preserved the extreme ends of the stainless clad bars. No delamination of the cladding and core of stainless clad bar under axial compression in a concrete column under corrosion was observed. In this aggressive simulated environment there was no loss of capacity as a result of end cap failure, since concrete spalling in columns reinforced with stainless clad vertical bars was also present in all-stainless reinforced columns. In terms of total mass loss per unit of applied energy, the all-stainless steel columns and the columns with stainless clad vertical bars and stainless steel spirals experienced approximately half the mass loss per kilowatt hour of specimens reinforced with grade 60 carbon steel, as shown in Table 3.

\section{Experimental results of axial compression tests}

The axial compressive strength of each column was compared for the corroded and control specimens of the three series. Corrosion was prevalent in the bottom $66 \%$ of the column height; CFRP was applied at the two ends for a height of $25 \%$ of the column height; hence the middle half of the column was corroded and not covered with CFRP or grout. The loading procedure was as follows: a concentric axial monotonic load was applied using displacement control at a rate of $2.54 \mathrm{~mm} / \mathrm{min}$. The critical displacement was measured at failure, defined here as the point after peak strength where the stress drops to $85 \%$ of the peak strength. Displacement measurements were taken from a pair of external LVDT's held with springs between two L-brackets, which were glued to the column surface, as shown in Fig. 8. Tables 4 and 5 summarize the quantitative results and relative capacities of the control and corrosion specimens, respectively.

An average maximum compression force equal to $3255 \mathrm{kN}$ was achieved for the control carbon steel reinforced specimens, as shown in Table 4, while the corroded specimens averaged $3021 \mathrm{kN}$, as shown in Table 5. This amounts to a $7.0 \%$ loss in maximum axial compressive strength, accompanied by a $15.0 \%$ reduction in average displacement at failure between the control and corroded specimens.

The axial compression force versus axial displacement for the control and corroded specimens is shown in Figs. 9 and 10, respectively. In addition to reaching a lower ultimate force capacity, the corroded columns had

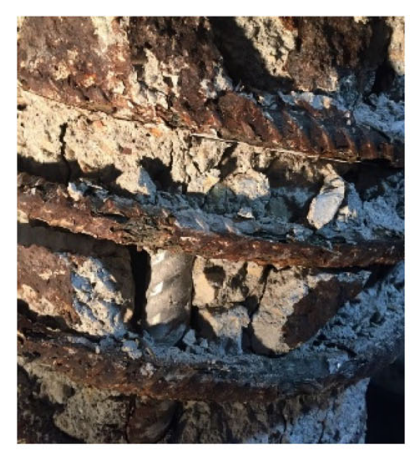

(a)

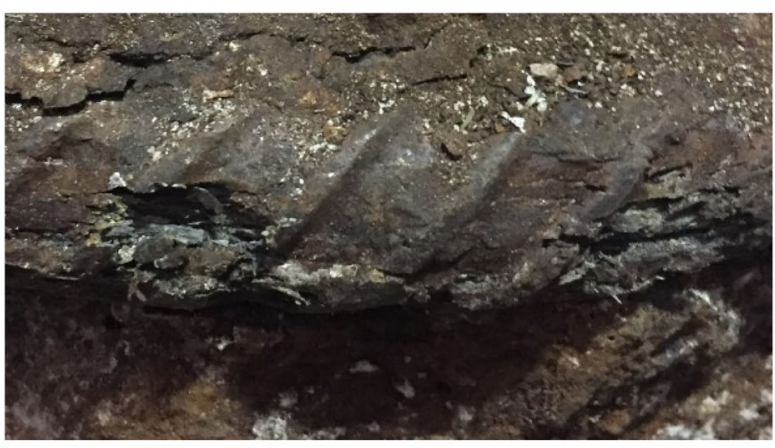

(b)

Fig. 6 Localized pitting on stainless steel spiral of specimen NN-R-2: a general view; b detailed view of single corrosion pit 


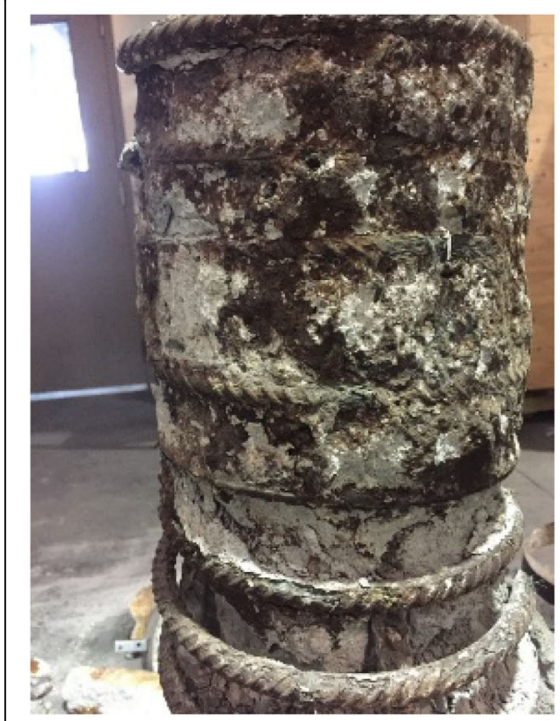

(a)

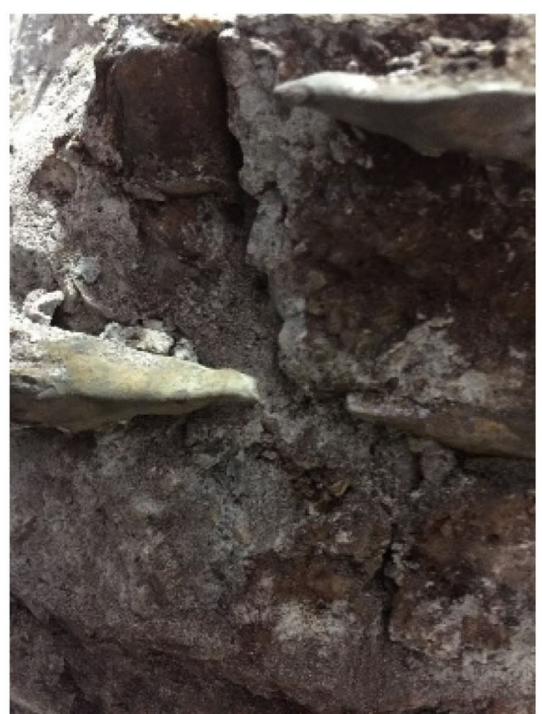

(b)

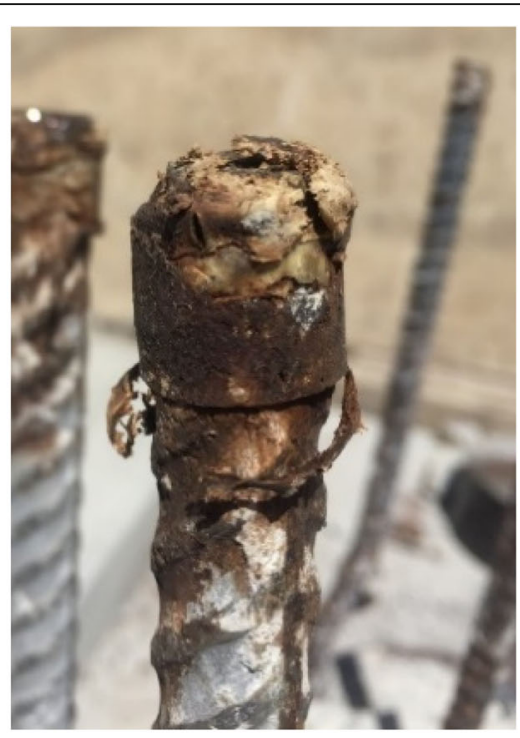

(c)

Fig. 7 Corrosion of specimen CN-R-1: a vertical concrete cracks; b necking of stainless steel spiral; c stainless steel end cap on stainless clad vertical bar

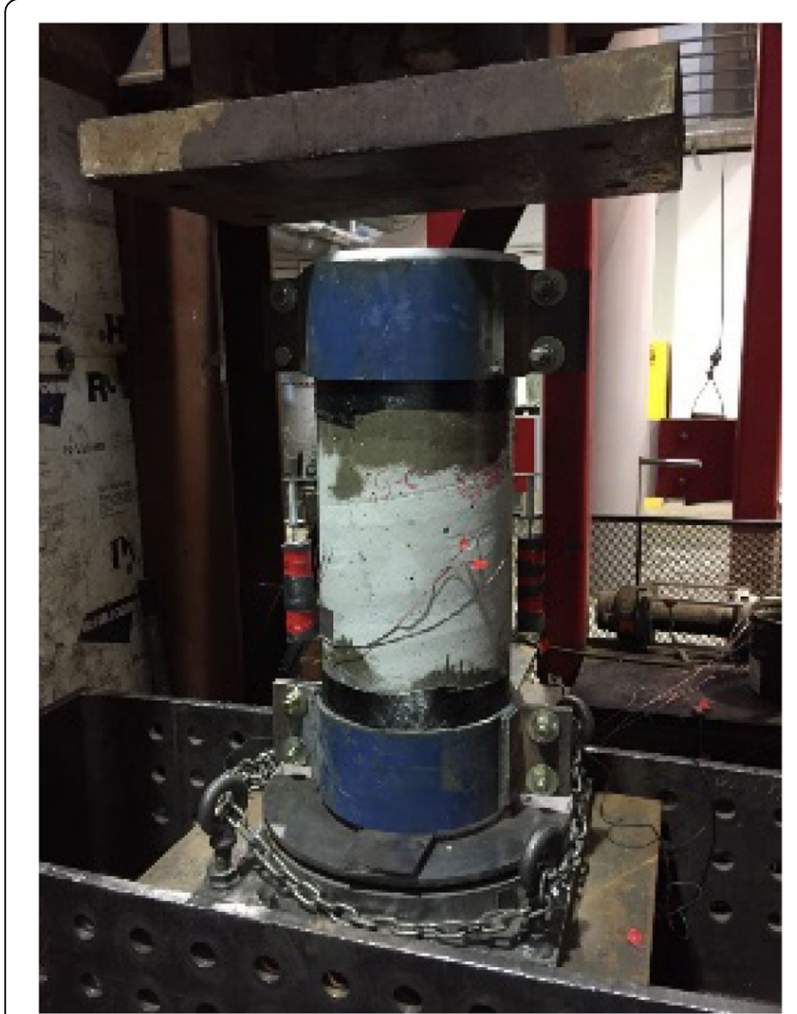

Fig. 8 Axial compression test setup with two LVDTs lower ultimate displacement capacity prior to failure, exhibiting lower ductility. Many corroded columns showed a more severe drop in axial compressive ultimate force after initial yielding than the control columns, indicating that greater damage had likely occurred as a result of reinforcement yielding due to corrosion prior to the confined concrete strength being fully developed.

BB-R-2 reached a similar force at the point of yielding when compared to the control specimens as shown in Fig. 11. This specimen is of note as it was the only specimen in the study that failed suddenly at a much lower displacement than any of the other specimens, failing prior to reaching its projected maximum axial compression capacity, as seen by the trajectory of its plot in Fig. 11. BB-R-1 yielded at a lower force but reached a higher maximum force than the other corroded specimen at a failure displacement that was comparable to the control columns. Despite lower losses in axial capacity overall, the BB series showed a risk for failure at low displacements, and even BB-R-1 reached a lower failure displacement than all specimens except NN-R-2, the most heavily corroded of the remaining specimens. Failure of specimen BB-R-1 is shown in Fig. 12c.

The higher ultimate strength of 2304 solid stainless steel enabled the control NN specimens to achieve an average compression capacity of $3548 \mathrm{kN}$ and displacement of $45 \mathrm{~mm}$. However, it is clear that the corroded $\mathrm{NN}$ columns were affected by mass loss more than the carbon steel BB columns. The corroded NN columns achieved an average compression capacity of $2932 \mathrm{kN}$, with an average loss of strength more than twice that of the BB columns. The average displacement of corroded 
Table 4 Comparison of axial compressive capacity of control specimens using experimental results and theoretical capacity from Eq.

\begin{tabular}{lllll} 
Specimen & Theo. Capacity (kN) & Exp. Capacity (kN) & Capacity Diff. (\%) & Exp. Critical Displ. (mm) \\
\hline BB-C-1 & 2740 & 3191 & -14.1 & 28.7 \\
BB-C-2 & 2740 & 3320 & -17.4 & 35.8 \\
NN-C-1 & 3150 & 3464 & -9.1 & 47.8 \\
NN-C-2 & 3150 & 3452 & -8.7 & 42.7 \\
CN-C-1 & 2988 & 3291 & -9.2 & 42.9 \\
\hline
\end{tabular}

NN columns was $33 \mathrm{~mm}$ or $27 \%$ less than the control specimens, largely driven by the especially low displacement reached by NN-R-2, as illustrated in Fig. 13; the figure also shows how NN-R-2 yielded at a much lower force when compared to the other corroded and control specimens in the $\mathrm{NN}$ series. Figure 12a shows column $\mathrm{NN}-\mathrm{R}-1$ which experienced sudden failure as the spiral broke at multiple places due to localized corrosion, thus becoming ineffective in restraining elastic bar buckling of the vertical bars; however, this failure was not as premature as that experienced by the carbon steel specimen BB-R-2. This mode of failure due to spiral fracture was also present in column NN-R-2. Corrosion of the stainless steel spiral reinforcement was the cause of capacity loss.

Specimens with stainless clad verticals and stainless steel spirals $(\mathrm{CN})$ performed similarly to the $\mathrm{NN}$ series, with control CN-C-1 specimen achieving a $3291 \mathrm{kN}$ compression capacity and $43 \mathrm{~mm}$ displacement. Specimen CN-R-2 showed greater compressive strength than CN-R-1 consistent with its lower theoretical mass loss; both exhibited a similar displacement at failure, but the more heavily corroded CN-R-2 failed suddenly while $\mathrm{CN}-\mathrm{R}-1$ failed gradually even after the spiral broke. Figure 14 shows how both corroded $\mathrm{CN}$ series specimens exhibited sharper drops in compression force after initial yielding, although they retained a greater degree of ductility than the corroded $\mathrm{BB}$ and $\mathrm{NN}$ series specimens; this is also shown in Fig. 10. Specimen CN-R-2 is illustrated at failure in Fig. 12b. Despite experiencing similar levels of mass loss as the $\mathrm{BB}$ series, the $\mathrm{CN}$ and $\mathrm{NN}$ series corroded specimens experienced greater reduction in axial compression capacity and displacement.

\section{Theoretical axial compression capacity of column specimens and comparison to experimental results}

Axial compression capacity of reinforced concrete columns is obtained as the sum of the compression capacity of the confined concrete and the longitudinal steel bars. The important parameter in this analysis is the confined concrete compressive strength contribution from spiral reinforcement; this is the case because the spiral material and its state of corrosion have the greatest influence on the overall column compression capacity.

\section{Theoretical models for confinement of concrete with spirals}

For carbon-steel reinforcement, the confinement model proposed by Mander et al. [12] gives accurate estimates of confined concrete strength. It is assumed that the stainless steel spiral performs similar to carbon steel and the Mander et al. [12] model applies. The model is given as:

$$
f_{c c}^{\prime}=f_{c o}^{\prime}\left(-1.254+2.254 \sqrt{1+\frac{7.94 f_{l}^{\prime}}{f_{c o}^{\prime}}}-2 \frac{f_{l}^{\prime}}{f_{c o}^{\prime}}\right)
$$

where $f_{c o}^{\prime}$ is the unconfined concrete compressive strength; the confining pressure $f_{l}^{\prime}$ is defined as:

Table 5 Comparison of axial compressive capacity of corroded specimens using experimental results and theoretical capacity from Eq. (9)

\begin{tabular}{lllllllll}
\hline Specimen & $\begin{array}{l}\text { Theo. Cap. } \\
(\mathbf{k N})\end{array}$ & $\begin{array}{l}\text { Exp. Cap. } \\
(\mathbf{k N})\end{array}$ & $\begin{array}{l}\text { Cap. Diff. } \\
(\mathbf{\%})\end{array}$ & $\begin{array}{l}\text { Mass Loss } \\
(\mathbf{\%})\end{array}$ & $\begin{array}{l}\text { Theo. Cap. Drop } \\
(\%)\end{array}$ & $\begin{array}{l}\text { Exp. Cap. Drop } \\
(\%)\end{array}$ & $\begin{array}{l}\text { Cap. Loss/Energy } \\
\text { (\%/kwh) }\end{array}$ & $\begin{array}{l}\text { Exp. Crit. Displ. } \\
\text { (mm) }\end{array}$ \\
\hline BB-R-1 & 2470 & 2981 & -17.1 & 27.2 & 9.9 & 8.4 & 0.90 & 26 \\
BB-R-2 & 2557 & 3061 & -16.5 & 18.9 & 6.7 & 6.0 & 0.60 & 37 \\
NN-R-1 & 2875 & 3132 & -8.2 & 18.4 & 8.7 & 10.0 & 0.80 & 36 \\
NN-R-2 & 2827 & 2732 & 3.5 & 22.6 & 10.3 & 22.3 & 1.5 & 31 \\
CN-R-1 & 2760 & 2872 & -3.9 & 21.0 & 7.6 & 12.7 & 0.89 & 39 \\
CN-R-2 & 2816 & 3044 & -7.5 & 16.1 & 5.8 & 7.5 & 0.69 & 35 \\
\hline
\end{tabular}




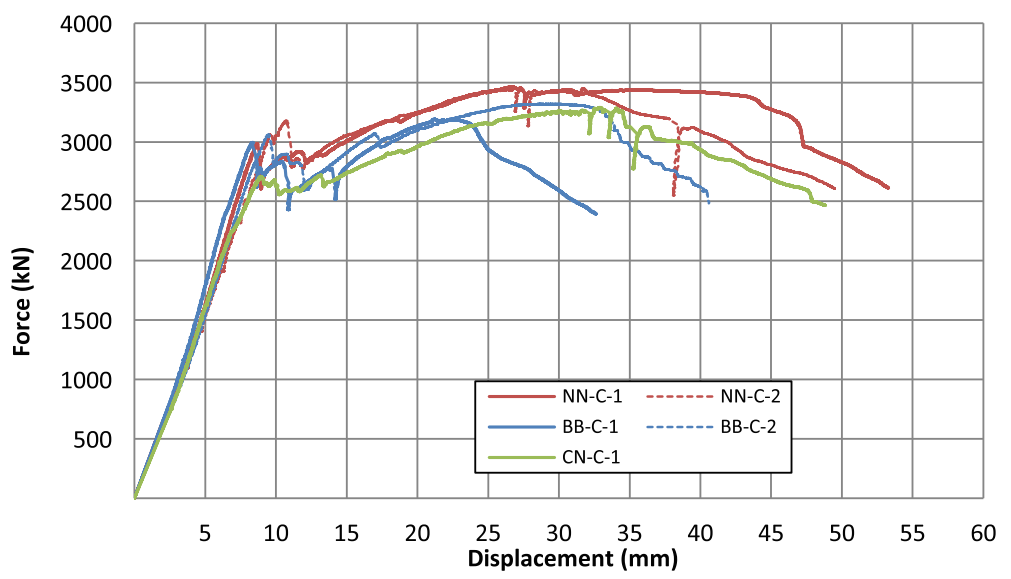

Fig. 9 Compression force versus axial displacement of control specimens

$$
f_{l}^{\prime}=\frac{2 f_{y h} A_{s p}}{D^{\prime} s} k_{e}
$$

where $f_{y h}$ is the yield strength of the transverse reinforcement, $A_{s p}$ is the area of the steel spiral, $D^{\prime}$ is the interior diameter of the spiral, $s$ is the spiral pitch, and $k_{e}$, is the confinement effectiveness given as:

$$
k_{e}=\frac{1-\frac{s}{2 d_{s}}}{1-\rho_{c c}}
$$

where $\rho_{c c}$ is the longitudinal reinforcement ratio with respect to the concrete core enclosed by the centerline of the spiral. For all-metallic reinforced columns $k_{e}$ is equal to 0.907 .

Once the confined concrete strength was found using the Mander et al. [12] model, the overall axial compression capacity of the columns $P_{n}$ was determined as:

$$
P_{n}=0.85\left[0.85 f_{c c}^{\prime}\left(A_{g}-A_{s}\right)+f_{y} A_{s}\right]
$$

The theoretical capacity of the control specimens is presented in Table 4, as well as the difference from the experimental average. In general, good agreement is observed between Eq. (7) and the experimental capacity; columns reinforced with carbon steel vertical bars and spirals showed a larger difference between theoretical and experimental capacity compared to columns reinforced with stainless steel and stainless clad vertical bars and stainless steel spirals.

For the corroded columns, the theoretical mass loss was used to determine the percentage of steel mass loss (or area), and confinement was calculated using the adjusted value. Corrosion had occurred mainly in the spiral; it was assumed that all of the corrosion-induced reduction in cross-sectional area occurred in the spiral.

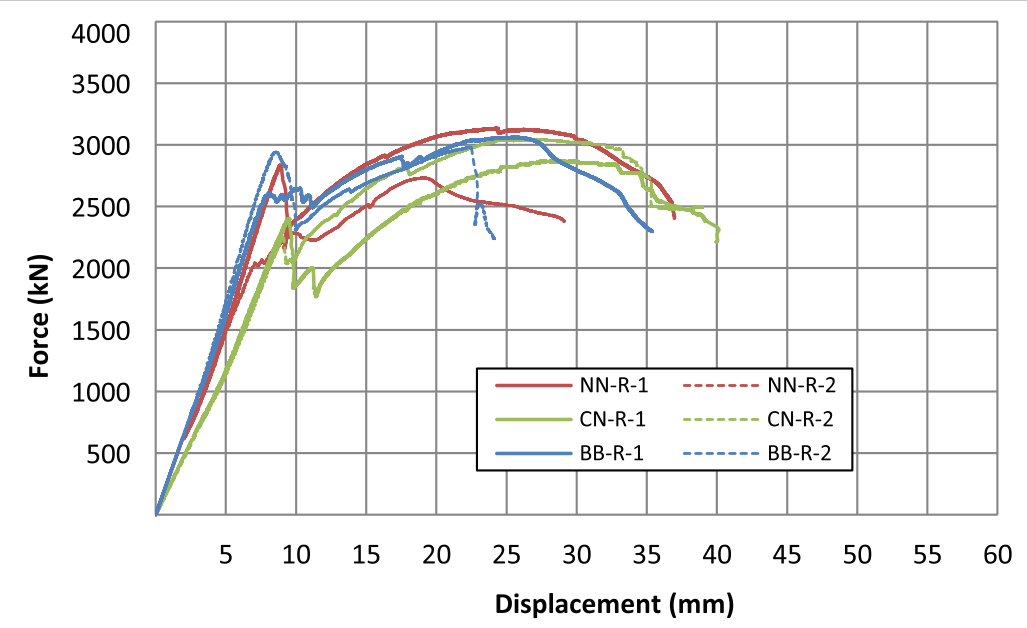

Fig. 10 Compression force versus axial displacement of corroded specimens 


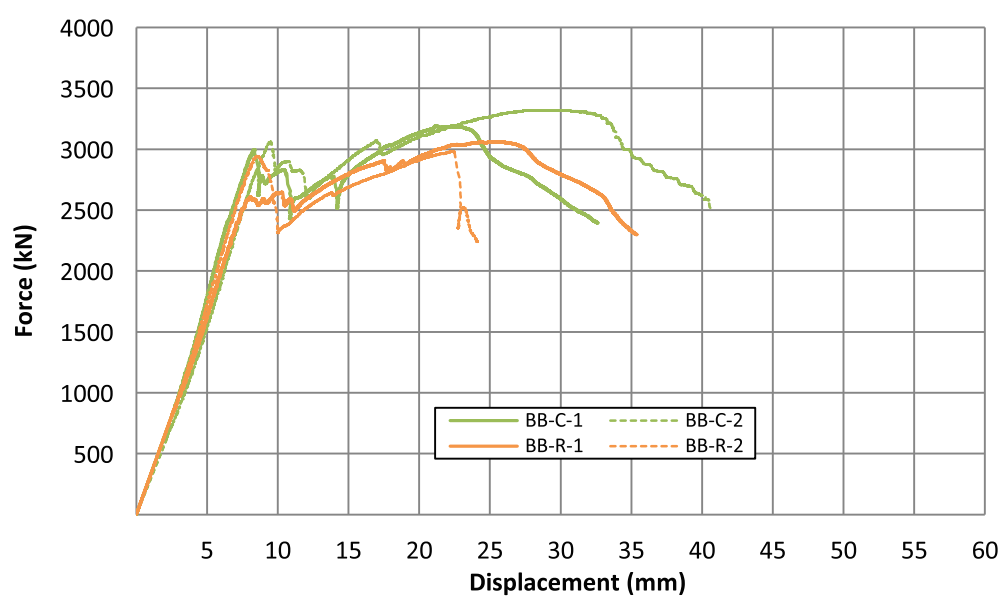

Fig. 11 Compression force versus axial displacement for BB series specimens with carbon steel vertical bars and carbon steel spiral

The expression used for the confining pressure of corroded metallic spirals is:

$$
f_{l c}^{\prime}=\frac{2 f_{y h}\left[A_{s p} *\left(1-M_{l}\right)\right]}{D^{\prime} s} k_{e}
$$

where $M_{l}$ is the theoretical percent of mass loss as a result of corrosion. The term $f_{l c}^{\prime}$ in Eq. (8) replaces $f_{l}^{\prime}$ in Eq. (4), with the modified confined concrete strength substituted into Eq. (7) to account for the reduced spiral section due to corrosion. Reducing the theoretical axial compressive capacity proportionally to the vertical reinforcement area loss results in:

$$
P_{n}=0.85\left[0.85 f_{c c}^{\prime}\left(A_{g}-A_{s}\right)+f_{y} A_{s}\left(1-M_{l}\right)\right]
$$

The theoretical column capacity for the corroded columns is shown in Table 5, along with the difference from the experiments. In general, good agreement is observed between Eq. (9) and the experimental capacity; columns reinforced with carbon steel vertical bars and spirals showed a larger difference between theoretical and experimental capacity compared to columns reinforced with stainless steel and stainless clad vertical bars and stainless steel spirals.

\section{Comparison of theoretical to experimental axial compression capacity}

Theoretical predictions were for the most part quite accurate. The Mander et al. [12] model predicted a similar difference in capacity for control and corroded specimens. Axial compression capacity reduction was determined by comparing the theoretical values for corroded and control specimens and is summarized in Tables 4 and 5 . The experimental capacity exceeded the analytical estimate for all specimens except one of the corroded all-stainless steel specimens (NN-R-2), which overpredicted the experimental performance by $3.5 \%$. This specimen in particular experienced the second highest mass loss, concentrated in various regions in the spiral,

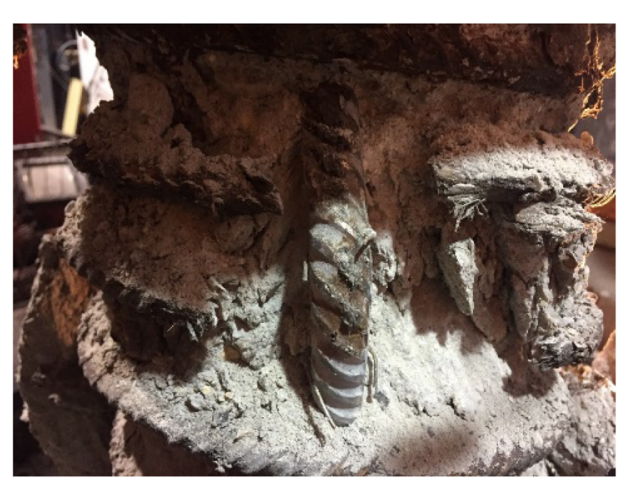

(a)

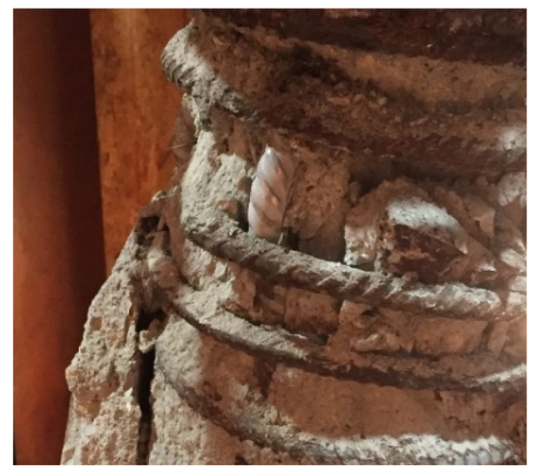

(b)

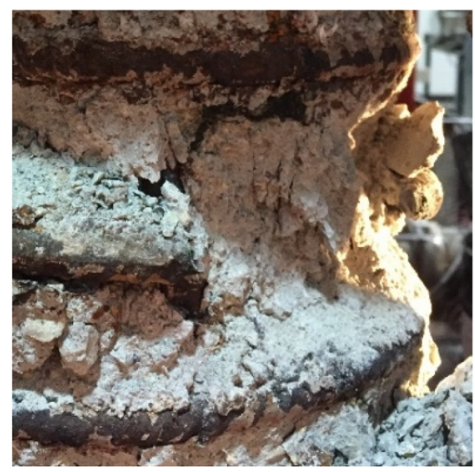

(c)

Fig. 12 Failure modes after axial compression tests: a multiple spiral fractures in NN-R-1; b spiral fracture and buckled vertical bars in CN-R-2; c fractured spiral in BB-R-1 


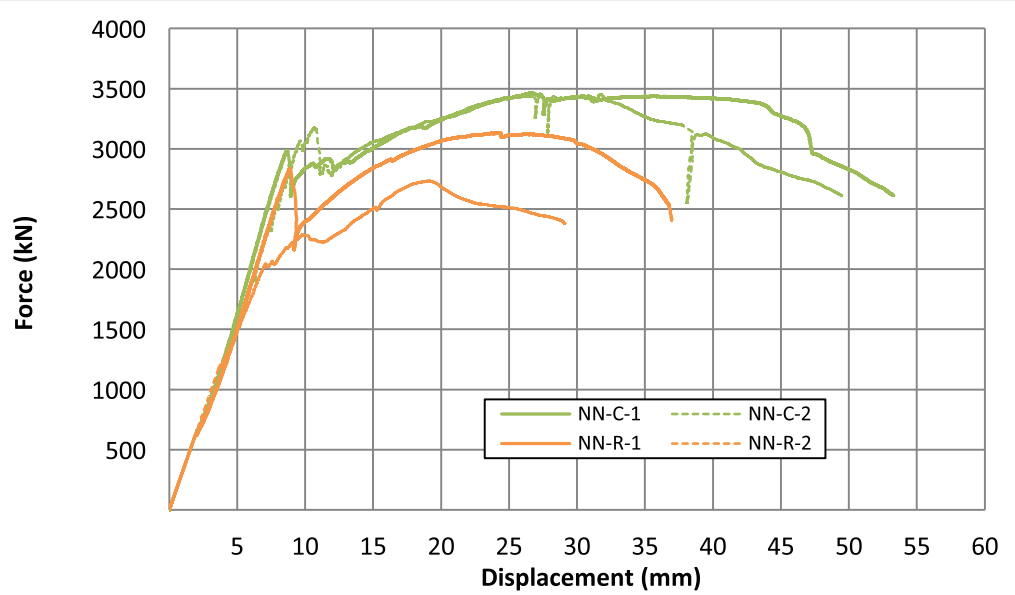

Fig. 13 Compression force versus axial displacement for NN series specimens with stainless steel vertical bars and stainless steel spiral

leading to a disproportionate drop in axial compressive capacity; a $22.3 \%$ drop in experimental compression capacity was measured for the all-stainless column NN-R-2, which was over twice the theoretical value of $10.3 \%$. The stainless steel spiral failed at discrete locations where most localized mass loss had occurred and is the cause of this discrepancy. This effect was observed for the CN series with stainless clad verticals and stainless steel spiral reinforcement. Compression capacity reduction in these specimens is not proportional to loss in spiral cross section beyond 18\% mass loss. Equation (8) applies only for cases where mass loss is below $18 \%$ in columns reinforced with 2304 solid stainless steel spiral.

The possibility that the axial compression capacity of the solid stainless steel bars could be sensitive even to low amounts of mass loss is obvious. This contrasts with the stainless clad verticals, which showed no such sensitivity, and had no compression capacity reduction compared to the control specimens.
In terms of total mass loss per unit of energy, allstainless and stainless/clad reinforced columns had approximately half of the mass loss per kilowatt hour of specimens reinforced with carbon steel. Localized concentration of mass loss had a profound impact on the performance of the all-stainless and stainless clad/stainless columns. The percentage of axial compression capacity reduction between corroded and control columns in terms of total corrosion energy is expressed as:

$$
C R_{c c}=\frac{\text { \%axial load capacity drop }}{E_{\text {total }}}
$$

The results are summarized in Table 5 and Fig. 15 which show axial compression capacity reduction as a function of total corrosion energy. Axial compression capacity reduction was severe as the amount of corrosion energy increased; the increase is much more pronounced for the $\mathrm{NN}$ series and $\mathrm{CN}$ series specimens.

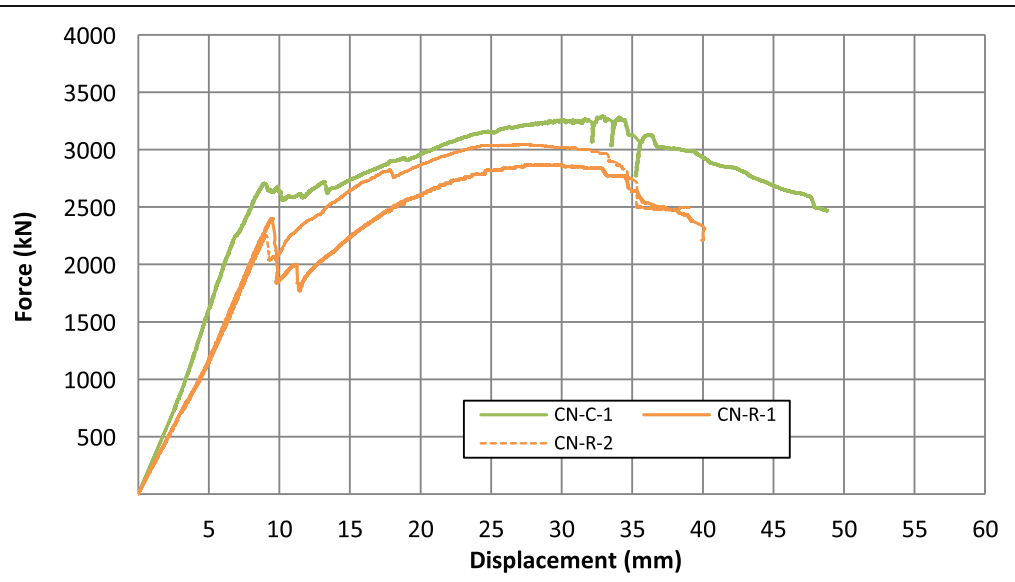

Fig. 14 Compression force versus axial displacement for $\mathrm{CN}$ series specimens with stainless clad vertical bars and stainless steel spiral 


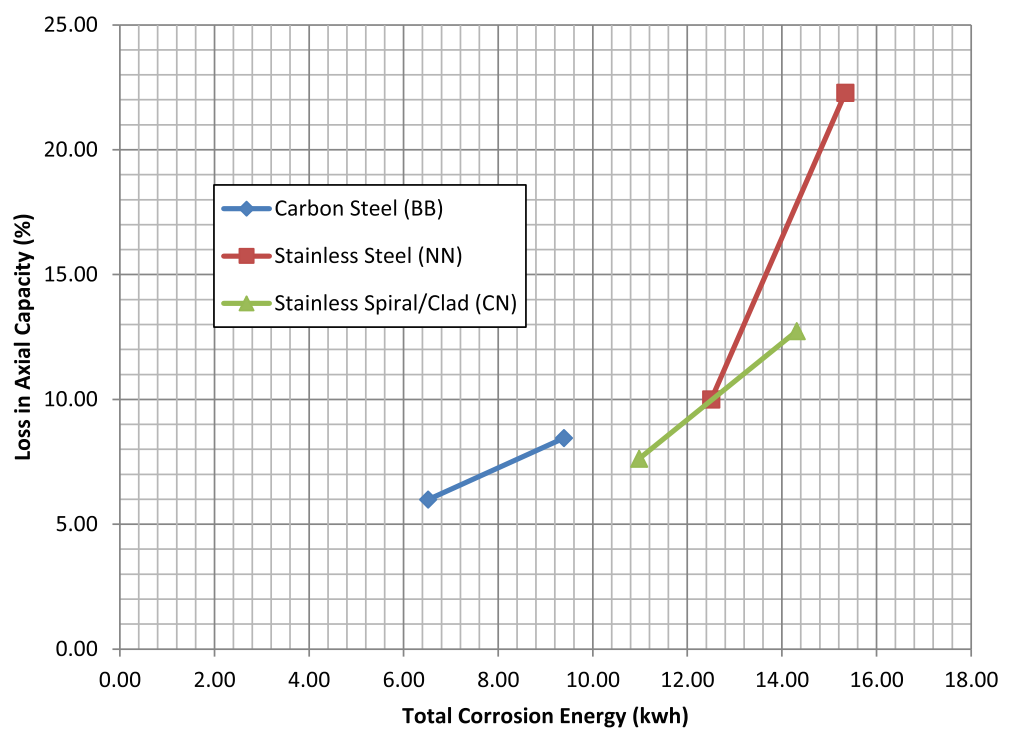

Fig. 15 Axial compression capacity loss in terms of total corrosion energy

Columns BB-R-1, CN-R-2, and NN-R-1 have a similar percentage of capacity loss due to corrosion, while the amount of energy required to cause that loss was 9.4, 10.1 , and $12.5 \mathrm{kWh}$, respectively. This represents $17 \%$ more energy for the $\mathrm{CN}$ series specimen and 34\% more energy for the $\mathrm{NN}$ series specimen when compared to carbon steel specimens. Neither of the carbon steel reinforced specimens experienced more than $9.4 \mathrm{kwh}$ of total corrosion energy, while specimens CN-R-1 and NN-R-2 experienced $14.3 \mathrm{kwh}$ and $15.3 \mathrm{kwh}$, respectively, which caused higher axial compression capacity reduction.

Figure 16 shows the axial compression capacity reduction as a function of mass loss; the axial compression capacity of stainless $(\mathrm{NN})$ and stainless clad columns $(\mathrm{CN})$ is more sensitive to mass loss when the latter exceeds $18 \%$. Localized areas of section loss in the stainless steel spiral had a greater impact on axial compression capacity than the distributed corrosion experienced by carbon steel spirals.

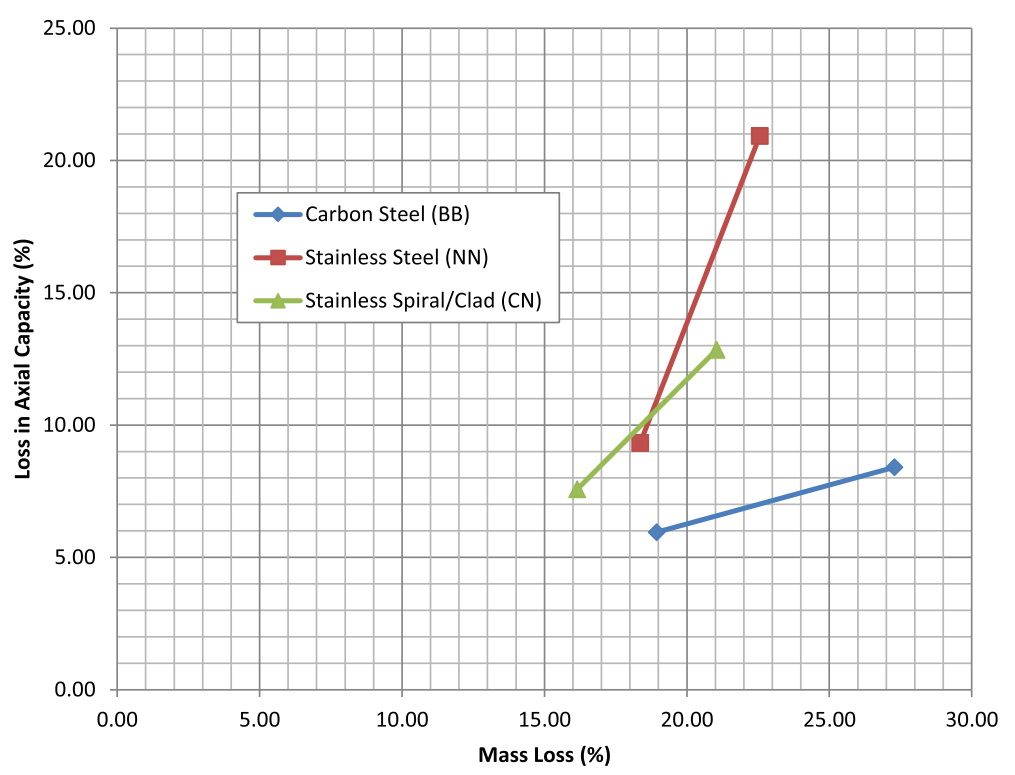

Fig. 16 Axial compression capacity loss in term of mass loss 


\section{Conclusions}

The corrosion performance and axial compression capacity of medium-scale concrete columns reinforced with combinations of corrosion-resistant reinforcement was investigated. The specimens reinforced with corrosionresistant reinforcement were compared to specimens reinforced with conventional carbon steel.

The specimens were subjected to accelerated corrosion at an impressed current density of $8.5 \mu \mathrm{A} / \mathrm{mm}^{2}$ for 60 days; the following conclusions are reached: (1) stainless steel and stainless clad vertical reinforcement had very similar performance in axial compression; both reinforcement types contributed to greater capacity overall than traditional carbon steel; (2) no delamination of the cladding from the core of $316 \mathrm{~L}$ stainless clad bars under axial compression in a concrete column under corrosion was observed, however, mechanical crimping is required to ensure integrity of stainless steel caps employed to protect 316 L stainless clad bars; (3) 2304 solid stainless steel reinforcement experienced corrosion and localized pitting, which caused localized concrete spalling; concrete cover was compromised when mass loss of stainless steel reinforcement exceeded 6.0\%; (4) in terms of mass loss per unit of corrosion energy, columns reinforced with 2304 solid stainless steel vertical bars and spirals, and columns with $316 \mathrm{~L}$ stainless clad verticals and 2304 solid stainless steel spirals exhibited $197 \%$ the corrosion resistance of carbon steel; (5) carbon steel reinforced specimens reached lower failure displacements and a corroded carbon steel specimen was the only one to experience sudden failure prior to reaching its theoretical maximum compression capacity; (6) corroded specimens reinforced with $316 \mathrm{~L}$ stainless clad verticals and 2304 solid stainless steel spirals retained greater ductility compared to both allstainless steel and carbon steel reinforced specimens; (7) when mass loss exceeded 18\%, 2304 solid stainless steel and $316 \mathrm{~L}$ stainless clad reinforced columns experienced $150 \%$ to $250 \%$ greater loss in axial capacity than those reinforced with carbon steel; (8) the theoretical concrete confinement model underpredicted the axial compression capacity of control and corroded columns by an amount of $4 \%$ to $17 \%$.

\footnotetext{
Abbreviations

$A_{g}$ : Gross area of column; $A_{s}$ : Area of vertical reinforcement; $A_{s p}$ : Crosssectional area of spiral reinforcement; $C R_{c c}$ : Percentage of drop in axial compression capacity per unit corrosion energy; $C R_{\text {mass: }}$ : Corrosion resistance in terms of mass loss per unit energy; $D^{\prime}$ : Interior diameter of spiral; $d_{s}$ : Diameter of reinforcing spiral; $E_{\text {total }}$ Total corrosion energy; $F$ : Faraday's constant; $f^{\prime}{ }_{c c}$ : Confined concrete strength; $f^{\prime}{ }_{\text {co: }}$ : Unconfined concrete strength; $f_{i}^{\prime}$ : Confining pressure; $f_{i c}^{\prime}$ : Confining pressure from corroded transverse reinforcement; $f_{\mathrm{y}}$ : Yield stress of metallic reinforcement; $f_{y h}$ : Yield strength of transverse reinforcement; $I_{\text {app: }}$ : Average applied current; $I_{\text {avg: }}$ Average current; $k_{e}$ : Confinement effectiveness ratio; $M_{A}$ : Atomic mass; $M_{\text {th }}$ : Theoretical mass loss; $M_{i}$. Theoretical mass loss percentage; $P_{n}$ : Axial compression capacity; $s$ : Spiral pitch; $T$ : Time; $v$ : Valency; $V_{\text {avg: }}$ Average applied voltage; $\rho_{c c}$ : Longitudinal reinforcement ratio
}

\section{Acknowledgements}

This study was partially supported by the National Center for Transportation Infrastructure Durability \& Life-Extension and the Mountain Plains Consortium. Materials were donated for 2304 solid stainless steel by Outo Kumpu, and for stainless-steel clad bars by Cladinox. The authors would like to thank Mark Bryant of the Department of Civil and Environmental Engineering at the University of Utah.

\section{Authors' contributions}

JWW conducted the experiments and analysis and wrote the draft. CPP developed the research plan and revised the draft. The author(s) read and approved the final manuscript.

\section{Funding}

This study was partially supported by the National Center for Transportation Infrastructure Durability \& Life-Extension and the Mountain Plains

Consortium.

\section{Availability of data and materials}

All data used or generated by this study is available from the corresponding author by reasonable request.

Ethics approval and consent to participate

Not applicable.

\section{Consent for publication}

Not applicable.

\section{Competing interests}

The authors declare that they have no competing interests.

\section{Author details}

${ }^{1}$ DMWPV, Richmond, VA 23225, USA. 2Department of Civil and Environmental Engineering, University of Utah, 110 Central Campus Drive, Room 2115, Salt Lake City, UT 84112, USA.

Received: 5 January 2021 Accepted: 9 February 2021

Published online: 19 February 2021

\section{References}

1. Mancio M, Cruz C, Zhang J, Harvey JT, Monteiro JM, Ali A (2008) Evaluation of corrosion resistance of steel dowels used for concrete pavements. J Mater Civ Eng 20(10):650-658

2. Duarte RG, Castela AS, Neves R, Freire L, Montemor MF (2013) Corrosion behavior of stainless steel rebars embedded in concrete: an electrochemical impedance spectroscopy study. Electrochim Acta 141:18-224

3. Cui F, Sagüés A (2003) Corrosion performance of stainless steel clad rebar in simulated pore water and concrete. Corrosion, Paper No. 03310, NACE International, Houton. 2003

4. Wu X, Li L, Li H, Li B, Ling Z (2018) Effect of strain level on corrosion of stainless steel bar. Constr Build Mater 163:189-199

5. Wu X, Ye D, Li H, Yu H (2018) Corrosion characteristics of $\$ 23043$ duplex stainless steel bars. Constr Build Mater 178:135-143

6. Ogunsanya IG, Strong V, Hansson CM (2020) Corrosion behavior of austenitic 304L and 316LN stainless steel clad reinforcing bars in cracked concrete. Mater Corros 71(7):1066-1080

7. Robert M, Benmokrane B (2013) Combined effects of saline solution and moist concrete on long-term durability of GFRP reinforcing bars. Constr Build Mater 38(C):274-284

8. Sun L, Mi X, Zhang X (2011) Experimental study on the compression performance of GFRP bars under different corrosion environments. Appl Mech Mater 71-78:1711-1174

9. Zhou A, Chow CL, Lau D (2018) Structural behavior of GFRP reinforced concrete columns under the influence of chloride at casting and service stages. Compos B Eng 136:1-9

10. Pantelides CP, Gibbons ME, Reaveley LD (2013) Axial load behavior of concrete columns confined with GFRP spirals. J Compos Constr ASCE 17(3): 305-313

11. Hales TA, Pantelides DP, Sankholkar P, Reaveley LD (2017) Analysis-oriented stress-strain model for concrete confined with fiber-reinforced polymer spirals. ACI Struct J 114(5):1263-1272 
12. Mander JB, Priestley MJN, Park R (1988) Theoretical stress-strain model for confined concrete. J Struct Div ASCE 114(8):1804-1826

13. Florida DOT (2000) Florida method of test for an accelerated laboratory method for corrosion testing of reinforced concrete using impressed current. Florida Department of Transportation, Tallahassee

14. El Maadawy TA, Soudki KA (2003) Effectiveness of impressed current technique to simulate corrosion of steel reinforcement in concrete. J Mater Civ Eng 15(1):41-47

15. Al-Sulaimani GJ, Kaleemullah M, Basunbul IA, Rasheeduzzafar (1990) Influence of corrosion and cracking on bond behavior and strength of reinforced concrete members. ACI Struct J 87(2):220-231

16. Almusallam AA, Al-Gahtani AS, Aziz AR, Dakhill FH, Rasheeduzzafar (1996) Effect of reinforcement corrosion on flexural behavior of concrete slabs. J Mater Civ Eng 8(3):123-127

17. Almusallam AA, Al-Gahtani AS, Aziz AR, Rasheeduzzafar (1996) Effect of reinforcement corrosion on bond strength. Constr Build Mater 10(2):123-129

18. Paewchompoo N, Yodsudjai W, Chindaprasirt P (2020) Corrosion-induced cracking time in steel fiber-reinforced concrete: experiment and finite element method. ACl Mater J 117(4):3-12

19. Trejo D, Halmen C, Reinschmidt K (2009) Corrosion performance tests for reinforcing steel in concrete. Technical report. Texas Transportation Institute, College Station

20. Ahmad S (2009) Techniques for inducing accelerated corrosion of steel in concrete. Arab J Sci Eng 34(2):95-104

\section{Publisher's Note}

Springer Nature remains neutral with regard to jurisdictional claims in published maps and institutional affiliations.

\section{Submit your manuscript to a SpringerOpen ${ }^{\circ}$ journal and benefit from:}

- Convenient online submission

- Rigorous peer review

- Open access: articles freely available online

- High visibility within the field

- Retaining the copyright to your article

Submit your next manuscript at $\boldsymbol{\nabla}$ springeropen.com 